\title{
Relationship of Mental Health to Religiosity
}

\author{
Christina L. Glenn*†
}

\begin{abstract}
The purpose of the present study was to examine the question of whether or not commitment to religious beliefs is associated with better mental health in typical community members. A household interview survey was conducted in a stratified, clustered sample of $3 \%$ of the adults that resided in a largely religious and rural mountain community. The Duke Health Profile was used to assess mental and physical health, and the nature and depth of religious devotion or commitment was based on the response to an interview item. Of the respondents in the sample, the mean age was 48.7 years, $55 \%$ were women, and the average annual family income was \$14 300 (US). In a simple unadjusted analysis, religiosity was significantly correlated with physical health (the ill were more religious) and gender (women were more religious), but not with mental health, age, income, education level, or geographic mobility. Mental health was correlated with gender (women scored lower), physical health (the ill scored lower), and income (the wealthy scored higher); but the correlations with these variables were largely in the opposite direction than religiosity. When the correlation between religiosity and mental health were adjusted for the economic, health, and demographic characteristics with the multiple partial correlation method, a definite correlation was found $(r=0.11$ to $0.14, p=0.005$ to 0.032$)$. The conclusion is drawn that there is an association between religious commitment and good mental health, but that it can be masked by the inverse dependencies of religion and mental health on economic, health and demographic factors. These results suggest that further investigation should be undertaken in order to elucidate the clinical utility of incorporating religious beliefs and practice into patient therapy.
\end{abstract}

\section{INTRODUCTION}

There is systematic and quantitative evidence that religious commitment and religious practice are associated with better physical and mental health. Religious devotion has been linked to greater life satisfaction and improved psychological health $(1,2,3)$, to lower incidence of depression $(4,5)$, and to lower incidence of psychiatric disorders in general (6). Levin and Vanderpool reviewed scores of studies that found an association between the frequency of church attendance

\footnotetext{
* To whom correspondence should be addressed: 3515 Honeywood Drive, Johnson City, Tennessee, USA., 37604.

$\dagger$ Kellogg Community Partnership Program, Colleges of Medicine, Nursing and Public Health, East Tennessee State University, Johnson City, Tennessee, USA
}

and physical health, although they urged that caution should be taken when interpreting such associations (7). Low levels of religious commitment have also been linked to increased alcohol consumption (8) and drug use $(9,10)$, and decreased self-care (11). The relation between health and religiosity has been established to be independent of denomination or religious affiliation (5).

Mental health can be defined as the absence of psychiatric disorders (as indicated by the Diagnostic and Statistical Manual-IV criteria (12)) such as depression, insomnia/sleep disorder and anxiety, as well as the absence of self-dislike or social difficulties. Selfesteem and life satisfaction are thus important aspects of this definition of mental health. Self esteem is defined as one's own evaluation of personal worth, while life satisfaction is a measure of whether one is 
happy or content with their life (see Methods).

Krause (13) conducted a study that focused on selfesteem in subjects with variable degrees of religiosity. Self-esteem was lowest, on average, in subjects that were somewhat religious. It was highest in subjects that were either highly religious or not religious. Two possible interpretations of this finding are: (i) knowing what you believe leads to a better self-image, or (ii) those with a high self-image tend to make decisions and have confidence in those decisions. Jensen et al. (5) conducted a similar study, with different results than Krause (13). Self-esteem was simply proportional to the degree of religiosity, such that those with the highest religiosity had the highest self-esteem. Jensen et al. (5) also found that those with high religiosity had lower levels of depression and a higher emotional maturity score. The above investigators were not able to statistically determine whether good mental health led to greater religiosity, or whether religiosity promoted good mental health, although it is expected that the latter is true.

There is also some evidence against the idea that religiosity is associated with improved mental health. Sorri et al. (14) have found a high incidence of intense religious activity in $18 \%$ of suicide victims, as well as a greater severity of mental illness in either deeply religious or completely non religious suicide victims. This contrasts with the findings of Krause (13) which suggest that self-esteem was highest in highly religious and non-religious groups, but was lowest in those of intermediate religious devotion. The issue of the role of religious commitment to mental health is consequently far from being settled.

The purpose of the present study was to investigate this issue by providing further data on the question of whether religious devotion is associated with better general mental health. The present study applied a standardized health questionnaire (Duke Health Profile) to a largely religious and rural population in a mountainous area, and adjusted for differences in demographic and physical health between religious and non-religious groups. The Duke Health Profile (15) is a standardized, widely-applied survey with 17 items grading the severity of general symptoms associated with poor physical and mental health, which results in a rating of both physical health and of mental health.

\section{METHODS}

\section{Setting}

The present study was approved by the Institutional Review Board of East Tennessee State University, Johnson City Medical Center, and Mountain Home Veterans Administration Center. It was conducted in a rural valley in a county in the northeast corner of Tennessee. The county (Johnson County) has only one incorporated town named Mountain City, with a population of 2139 (in 1990). The county was selected for the following reasons: (i) designated as $100 \%$ rural by the U.S. Census Bureau; (ii) designated as a Health Professions Shortage Area by the Department of Health and Human Services of the US Government; (iii) high poverty rate indicated by the finding that $43 \%$ had income under $\$ 15000$ (US) per year in the 1990 US Census; and (iv) proximity of the county to the researchers conducting the present project.

\section{Sample}

A systematic sample of households was taken from a list of addresses. The county was divided into 7 subregions and every person in 30 to 50 households in each subregion was interviewed. Residents that were 15 years of age or younger were interviewed by proxy through an adult living in the household. A total of 541 residents were selected for interview, with 15 refusing, for a total of 526 interviews in 220 households. This comprised $3 \%$ of the county population, and a $97.2 \%$ interview response rate. Of these, 402 were 16 years of age or older and are included in the present analysis.

Although this resulted in a total of 402 interviews, the interviewed residents did not always answer every question, but elected to skip some questions. Few questions were answered by all 402 residents. Most questions had at least a one or two missing responses due to response refusals, which dropped the effective sample size to 400 or 401 , respectively. The question that was most often unanswered by residents in the present study was the item on religiosity (see below). Only 367 residents answered this question, so any analyses based on it was limited to a maximum of 367 responses. When an analysis of this item was combined with another question that also had missing responses, the net number of responses was even lower than 367 . The exact number of complete responses is specified analysis-by-analysis in the results section.

The interviews were conducted by researchers, teachers, students and staff as part of an interdisciplinary rural health care curriculum conducted on site in Johnson County. The students and teachers were from the medical, nursing and public health schools of the East Tennessee State University. One of the researchers with expertise in interviewing techniques (Dr. Rubye Beck) trained both the students and staff interviewers in formal sessions, and familiarized the teachers with the survey.

\section{Instrument}

The interview was conducted using a 48-item survey, which included the Duke Health Profile (15) and selected items from the National Health Interview (16). 
The items covered the following five categories: demographic profile, mental and physical health status, household economic status, health care insurance availability and accessibility, and a qualitative portion concerning what the major problems were in that geographical area. The responses to the Duke Health Profile were totaled and divided into the two main scores of physical and mental health status (15). The mental health score is sensitive to relatively small changes in mental health and it can be applied to the general population; as such, it does not necessarily require symptoms that meet the criteria for DSM-IV classification. The items that comprise the mental health score can be divided into those concerned with selfesteem, depression, anxiety, and life satisfaction. Selfesteem was evaluated with the question, "How much do you like yourself?", while life satisfaction was assessed as the degree to which one agrees with the following statement, "I am satisfied with my life." The reliability and validity of both the Duke Health Profile and health items on the National Heath Interview Survey have been documented to be good predictors of health $(15,17)$.

Religiosity was considered a single dimension in the present study, and was defined by the subjects selfassessment of their depth of personal devotion and commitment. It should be recognized that it is possible to define different types of religiosity, such as the organizational, non-organizational, and subject types defined by Levin (18). LaPierre (19) argued that two dimensions are important: religiosity and spirituality. Nevertheless, a single dimension was used in the present study primarily to minimize the length of the survey while still capturing the most important aspect of religious feelings.

\section{Data Analysis}

The data were manually entered into a database and analyzed with the SPSS 7.5 program (SPSS Inc., Chicago, IL, U.S.A.). Since a non-random probability sample was used, the cases were weighted in order to compensate for the combination of clustering and stratification. Weights were relative weights of the sample selection type and were simply equal to the reciprocal of the probabilities that a case would be selected in each cluster or strata. After application of weights, the results were numerically equivalent to a county-wide random sample.

A descriptive univariate analysis was first conducted to characterize the sample. On the basis that there was a reciprocal interaction between religiosity and health, a stepwise multiple correlation analysis was conducted rather than the more customary multiple regression analysis. By interaction, it is meant that previous studies suggested that health status has an effect on religiosity and religiosity has an effect on health status $(1,2,4,5,6)$. Thus, a more general multiple correlation analysis was applied.

The item used to assess religiosity was the question, "How important would you say your religion is to you personally?", with the possible responses of: (i) very important, (ii) somewhat important, (iii) not very important, and (iv) not at all important. As described in the results section below, only 12 residents of 401 selected the latter two categories. The variable was consequently recoded into a dichotomous variable according to whether very important was selected (303 residents) or any other choice was selected (64 residents), to remedy, or at least minimize, the unevenness of the responses. The justification for using a correlation analysis with a dichotomous variable is as follows: the variable is the categorization of a normally distributed continuous variable that represents religiosity, such that most subjects are close to the average religiosity for the population, and there are fewer-and-fewer subjects with a given religiosity in both directions from the mean.

\section{RESULTS}

\section{Description of Sample}

The demographic characteristics of the residents are shown in Table 1. Of the 402 respondents in the sample, the mean age was 48.7 years and $55 \%$ were women. The residents of the county in the present study had relatively low incomes and less formal education than the average citizen in the United States. The average annual family income was $\$ 14300$ (US), which is about half of the average family income nationwide. Nearly half of the residents lived below the poverty line. The average level of formal education was the eleventh grade of high school. This indicates that about more than half of the residents in the sample did not graduate from high school. The average resident lived in the county for 9 years, and at their current address for 5 years, indicating the county had a stable composition of residents (i.e., relatively stationary). As compared to the national average, residents in this county are five years older, have a household income that is only $45 \%$ of the national average, and have four years less formal education (G. Burkett and R. Beck, unpublished results).

The key measures in the present study were selfreported (i) physical health status, (ii) mental health status and (iii) religiosity. The average scores are shown in Table 2. Eighty-three percent of the sample selected the maximum choice on the key religiosity item, which was "My religion is very important to me." Only 3\% indicated that religion is unimportant, with $14 \%$ indicating that religion was "somewhat important". As 
Table 1. Demographic features of the sample.

\begin{tabular}{|c|c|c|c|}
\hline & Mean & S.D. & $\mathbf{N}$ \\
\hline Age (years) & 48.7 & 19.0 & 402 \\
\hline Female $(\%)$ & 55.0 & - & 402 \\
\hline Married (\%) & 64.3 & - & 402 \\
\hline Single $(\%)$ & 14.7 & - & 402 \\
\hline Separated, Divorced, or Widowed (\%) & 11.0 & - & 402 \\
\hline Annual Income (US\$) & 14300 & 9530 & 383 \\
\hline Level of Formal Education (grade level) & 11.3 & 9.6 & 401 \\
\hline Time Lived in County (years) & 8.8 & 3.9 & 402 \\
\hline Time Lived at Current Address (years) & 5.2 & 1.9 & 402 \\
\hline
\end{tabular}

The sample size $(\mathrm{N})$ indicates the number of interviewees that answered the question. Table entries with a blank standard deviation (S.D. column) are categorical variables, for which S.D. is not applicable.

compared to the national average (C. Jijon and R. Beck, unpublished results), the physical health scores for county residents was lower by 20.4 score units, but there was little difference in mental health scores (1.5 score units lower). After recoding the religiosity item as described in the methods section, the relationship between the three key factors was determined by computing the correlation coefficient between them, as described next.

\section{Interdependence of Health, Religiosity, and the Demographic Profile}

The correlation between mental health and physical health was moderate and positive $(r=0.52, p<0.0005)$. This indicated that residents with a greater physical health had a greater mental health. If religion is correlated with either mental or physical health, it might be expected that it would also correlate with the other. In fact, there was a significant correlation between religiosity and physical health $(r=-0.11, p=0.02)$ consistent with other studies - for review see Levin and Vanderpool (6). However, the correlation between religiosity and mental health was weak and not statistically significant ( $r=0.06$, N.S.). The potential interaction between the factors of physical health, mental health, and religiosity is illustrated in Figure 1 and is further discussed later in this section.

The next analysis shows the relationship of physical health status, mental health status, and religiosity to the demographic variables (Table 3). The strongest correlate of religiosity was age, with religiosity increasing with age. This was followed by gender (women were more religious) and annual income (religiosity increases with income); however, the relationship with income fell short of statistical significance $(\mathrm{p}=0.06)$. With regard to the mental health score, the closest correlates were income, gender, and time residing in the county. Mental health was higher in men, in the wealthy, and in long time residents of the county. Lastly, physical health was most closely related to advancing age, gender (females were more healthy), income (the wealthier were healthier), and time in county (long-time residents were more healthy). Overall, age had the strongest effect. The education factor was not significantly related to any of the key variables. It is apparent that mental health and religiosity vary in association with not only physical health, but also with age, sex, economic status, and duration of residence in the county studied.

\section{Religiosity and Mental Health}

In the analysis above, many factors were found to influence mental health and religiosity in opposite directions. In Table 3, it can be seen that almost all of the demographic factors have a different sign for mental health and religiosity. For example, age is associated

Table 2. Religious and health characteristics of the sample. See Table 1 for details.

\begin{tabular}{|c|c|c|c|}
\hline & Mean & S.D. & $\mathbf{N}$ \\
\hline Physical Health Score (Range 0 - 100a) & 63.5 & 28.6 & 401 \\
\hline Mental Health Score (Range 0 - 100a) & 77.9 & 20.3 & 391 \\
\hline Protestant $(\%)$ & 100.0 & - & 385 \\
\hline Other $(\%)$ & 0.0 & - & 385 \\
\hline My Religion is Very Important to $\mathrm{Me}(\%)$ & 82.6 & - & 367 \\
\hline My Religion is Somewhat Important to Me (\%) & 14.4 & - & 367 \\
\hline My Religion is Not Very Important to Me (\%) & 3.0 & - & 367 \\
\hline
\end{tabular}

a A score of 100 represent the highest health score (Duke Health Profile)(15). 
Table 3. Correlation between demographic variables and key variables.

\begin{tabular}{lccccc}
\hline \hline & Age & Gender & Annual Income & Education Completed & Time in County \\
\hline Physical Health & $-0.41^{\mathrm{c}}$ & $-0.21^{\mathrm{c}}$ & $0.37^{\mathrm{c}}$ & 0.08 & $0.10^{\mathrm{a}}$ \\
Mental Health & -0.06 & $-0.21^{\mathrm{c}}$ & $0.26^{\mathrm{c}}$ & 0.07 & $0.10^{\mathrm{a}}$ \\
Religiosity & $0.24^{\mathrm{c}}$ & $0.12^{\mathrm{a}}$ & -0.08 & -0.01 & 0.05 \\
\hline \hline
\end{tabular}

a $p>0.05 ;{ }^{\mathrm{b}} p<0.01 ;{ }^{\mathrm{c}} p<0.001$ The analysis was limited to 341 of the 402 interviewees who answered all questions needed in this analysis. The numbers are Pearson's correlation coefficient (r).

with increased religiosity but decreased mental health. In Figure 1, it can be further seen that physical health has different directions of association with mental health and religiosity, such that diminished physical health is associated with diminished mental health but increased religiosity. Given the opposing, but mutual, dependence of religiosity and mental health on so many other factors, the true relation between these two can only be determined if the many opposing factors are taken into account. This was accomplished with a hierarchical, step-wise, multiple correlation analysis. The results are shown in Table 4.

When the correlation between religiosity and mental health was not adjusted by any factor, it was insignificant (Step 1 of Table 4). When adjusted for either physical health (Step 2), for all demographic factors (Step 3), or both (Step 4), a statistically significant correlation of between 0.10 and 0.14 was found. The fact that the correlation was relatively stable over a wide selection of adjusting factors supports the concept that the depth of religious belief and mental health are linked. When the same correlation in Step 4 was conducted incorporating the individual items that comprise the mental health score, the most significant items were those related to self-esteem and life satisfaction (see Introduction and Methods for definitions). The relation between religiosity and mental health was thus uncovered, but this relation was only apparent after the complicating interactions of health and demographic factors were taken into consideration.

\section{DISCUSSION}

The present study finds that there is a definite relation between religiosity and mental health in the study population, with mental health improving as the personal importance of religion increases. The relationship is underestimated, however, unless the mutual dependence of religiosity and mental health on physical health (or its correlates) is taken into consideration.

The results supports those of many other studies that have found an association between measures of religiosity and mental health. Kaldestad et al. (1) found a relationship between psychological health and religiosity. Coke (2) and Ho et al. (3) found a higher total life satisfaction in those with a higher religiosity.
Koenig et al. (6) found those with a low frequency of church attendance to have a greater likelihood to have psychiatric disorders. Kendler et al. (4) conducted a study considering the relation between religious devotion and mental health in twins. Religiosity, defined as personal devotion, was found to be inversely related to depression. There was no relation found, on the other hand, between religiosity and the presence or absence of psychiatric disorders. The mental health score of the Duke Health Profile is heavily weighted towards the assessment of depression and anxiety, so the findings of Kendler et al. (4) are consistent with the present study.

Jensen et al. (5) found that scores on tests that measure self-esteem and emotional maturity were higher, and that depression was lower, in those that had a higher religiosity. Moreover, this relation was independent of specific denomination. The depth of religious devotion was independent of denomination in the present study as well, although the subjects in the present study were more uniform than the subjects

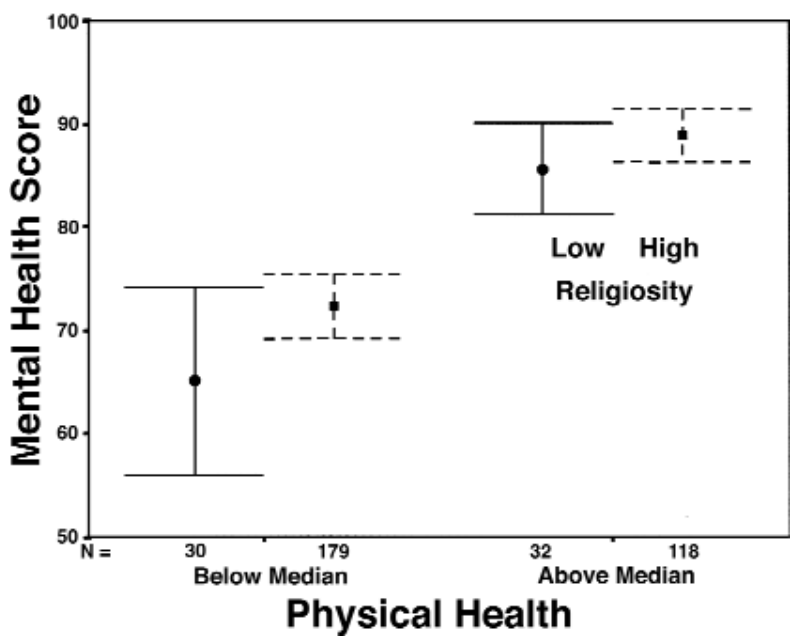

Figure 1. Plot Showing dependence of relation between religiosity and mental health on physical health. The vertical axis is the mental health score from Duke Health Profile: the higher the score, the greater the mental health. The horizontal axis shows four groups into which the sample was divided: low physical health and low religiosity, low physical health and high religiosity, high physical health and low religiosity, high physical health and high religiosity (from left to right). The points show the mean mental health score for each of the four groups, and the brackets show the $95 \%$ confidence intervals. 
studied by Jensen et al. (5). In the present study, all subjects were Protestant, and the majority were Baptist or non-denominational Christian. Krause (13) found evidence that religiosity and self-esteem were related, but that self-esteem was highest in both the highly religious and the non-religious groups, with those of intermediate religiosity having the lowest self-esteem. There was evidence for this in the current study's population as well. A re-analysis of the self-esteem score of the Duke Health Profile found the highest selfesteem scores were for those who indicated that their religion was "not at all" important; however, their numbers were small, and thus statistical significance was not obtained (data not shown). Nevertheless, these findings are consistent with the findings of Krause (13).

One of the secondary findings of the present study was that age was not significantly related to religiosity, although there was a trend in this direction. This finding largely substantiates the findings of several other research groups. Levin et al. (18) found that religiosity was correlated with physical health and life satisfaction over the entire life span. Age was not an important determinant of the degree of religiosity or its interaction with other characteristics. A 4-year longitudinal study also concluded that religious commitment and practice were relatively stable over time (20). Hunsberger (21) found that changes in religiosity changed with age and were barely detectable, but that this hid a divergence: some subjects became more religious with age and others less religious. Although it is possible that the current sample could have diverged with age, this could not be tested because no items were included that considered changes in religious devotion over time. Nonetheless, the present findings are consistent with previous studies showing that age is not generally a very important factor in religiosity.

In addition to age, the findings from the current study also substantiate another finding reported previously, namely that women have a higher religiosity than men $(2,22,23)$. In fact, this relationship tended to blur the connection between religion and mental health in the same way that the relationship of physical health blurred the connection. After these complicating factors were removed, through the use of step-wise partial correlation, it became clear that mental health and religion were significantly related, at least in the present population.

One of the limitations of the study is that both religiosity and mental health are measured by the responses of interviewed subjects. It is important to consider the possibility that subjects were not accurate in their responses. At worse, the findings would indicate that people who say they have good mental health also say they are religious, and the two factors are actually
Table 4. Step-wise multiple correlation analysis of relation between religiosity and self-reported mental health status measured by the Duke Health Profile.

\begin{tabular}{llcc}
\hline \hline Step & Adjusting Variables & Correlation $(\boldsymbol{r})$ & Significance $(\boldsymbol{p})$ \\
\hline 1 & None & 0.060 & 0.128 \\
2 & Physical Health & 0.135 & 0.005 \\
3 & Age & 0.101 & 0.032 \\
& $\begin{array}{l}\text { Gender } \\
\text { Income } \\
\text { Education } \\
\text { Years in County }\end{array}$ & & \\
& Physical Health \\
Age & 0.108 & \\
Gender & & \\
Income & & \\
Education & & \\
Years in County & & \\
& & \\
\hline
\end{tabular}

The analysis was limited to 341 of the 402 interviewees who answered all questions needed in this analysis. The $r$ is the correlation coefficient between mental health and religiosity, before and after adjustment for multiple factors.

not related. This possibility cannot be ruled out by the present study or by other studies in the literature. This possibility has been ruled out, however, for the relation between physical health and religiosity (7).

The present study was conducted in a population that is largely rural, religious, and of low income. Consequently, the findings may not be assumed to be the same in other populations. The stepwise analysis of Table 4 does, however, take into account the different income and education of different subjects. In fact, these had to be taken into account to elucidate the connection between religion and mental health. This, in turn, implies that a population with only a different socioeconomic status would be expected to show this same relation.

Another issue that needs to be resolved by further research is the main direction of the cause and effect. Does religiosity cause better mental health? Or does better mental health cause higher religiosity? Or do both affect each other equally, in a balanced way? It is also possible that the two are associated because a third unknown factor causes increased religiosity and mental health. The results of this study suggest that further investigation should be undertaken in order to elucidate the clinical utility of incorporating religious beliefs and practice into patient therapy.

An analysis of the Duke Health Profile in a largely religious and rural population has determined that there is a definite association between the personal importance of religion and mental health, particularly for aspects of mental health related to self-esteem and 
life satisfaction. The association between religion and mental health, however, was suppressed by counter relationships with physical health and demographic factors. This finding points to the need to adjust for age and physical health when studying this problem, and may account for some of the inconsistencies in previous religion-mental health studies. The present authors support the calls of Kroll (24) for more research on the role of religion in mental health, and of Neeleman and Persaud (25), for a greater appreciation by psychiatrists of the linkage between religious commitment and good mental health.

\section{ACKNOWLEDGMENTS}

The author thanks the faculty and students of the Kellogg Community Partnerships Project who conducted this survey, and the Office of Rural and Community Health, which distributed the Johnson County Health Survey database. Thanks are also due to Drs. Gary Burkett and Rubye Beck of the Research Division of the Department of Family Medicine at Quillen College of Medicine for originating the Johnson County Health Survey, and also to the Office of Research Services of the College of Nursing at East Tennessee State University for statistical support.

\section{REFERENCES}

1. Kaldestad E. The empirical relationships between standardized measures of religiosity and personality/mental health. Scandinavian Journal of Psychology 37(2):205-220; 1996.

2. Coke MM. Correlates of life satisfaction among elderly African Americans. Journal of Gerontology 47(5):316-320; 1992.

3. Ho SC, Woo J, Lau J, et al. Life satisfaction and associated factors in older Hong Kong Chinese. Journal of the American Geriatrics Society 43(3):252-255; 1995.

4. Kendler KS, Gardner CO, Prescott CA. Religion, psychopathology, and substance use and abuse; a multimeasure, genetic-epidemiologic study. American Journal of Psychiatry 154(3):322-329; 1997.

5. Jensen LC, Jensen J, Wiederhold T. Religiosity, denomination, and mental health among young men and women. Psychological Reports 72(3 Pt 2):1157-1158; 1993.

6. Koenig HG, George LK, Meador KG, et al. Religious affiliation and psychiatric disorder among Protestant baby boomers. Hospital and Community Psychiatry 45(6):586-596; 1994.

7. Levin JS, Vanderpool HY. Is frequent religious attendance really conducive to better health? Toward an epidemiology of religion. Social Science and Medicine 24(7):589-600; 1987.
8. Brown DR, Gary LE. Religious involvement and health status among African-American males. Journal of the National Medical Association 86(11) :825-831; 1994.

9. Amey $\mathrm{CH}$, Albrecht SL, Miller MK. Racial differences in adolescent drug use: the impact of religion. Substence Use and Misuse 31(10):1311-1332; 1996.

10. Cronin C. Religiosity, religious affiliation, and alchohol and drug use among American college students living in Germany. International Journal of the Addictions 30(2):231-238; 1995.

11. Astedt-Kurki P. Religiosity as a dimension of well-being: a challenge for professional nursing. Clinical Nursing Research 4(4):387-396; 1995.

12. American Psychiatric Association. Diagnostic and Statistical Manual of Mental Disorders, 4th edition. Washington DC: American Psychiatric Association; 1994.

13. Krause N. Religiosity and self-esteem among older adults. Journal of Gerontology, Series B, Psychological Sciences and Social Sciences 50(5):P236-P246; 1995.

14. Sorri H, Henriksson M, Lionnqvist J. Religiosity and suicide: findings from a nationwide psychological autopsy study. Crisis 17(3):123-127;1996.

15. Parkerson GR Jr, Broadhead WE, Tse CK. The Duke Health Profile: a 17-item measure of health and dysfunction. Medical Care 28(11):1056-1072; 1990.

16. National Center for Health Statistics. Current estimates from the National Health Interview Survey, 1991 (Series 10, Number 183). Hyattsville, MD: Department of Health and Human Services; 1992.

17. Gold M, Franks P, Erickson P. Assessing the health of the nation. The predictive validity of a preference-based measure and selfrated health. Medical Care 34(2):163-77; 1996.

18. Levin JS, Chatters LM, Taylor RJ. Religious effects on health status and life satisfaction among black Americans. Journal of Gerontology, Series B, Psychological Sciences and Social Sciences 50(3):S154-S163; 1995.

19. LaPierre LL. The spirituality and religiosity of veterans. Journal of Health Care Chaplain 6:73-82; 1994.

20. Markides KS. Aging, religiosity, and adjustment: a longitudinal analysis. Journal of Gerontology 38(5):621-5; 1983.

21. Hunsberger B. Religion, age, life satisfaction, and perceived sources of religiousness: a study of older persons. Journal of Gerontology 40(5):615-620; 1985.

22. Levin JS, Taylor RJ. Gender and age differences in religiosity among black Americans. Gerontologist 33(1):16-23; 1993.

23. Levin JS, Taylor RJ, Chatters LM. Race and gender differences in religiosity among older adults: findings from four national surveys. Journal of Gerontology 49(3):S137-S145; 1994.

25. Neeleman J, Persaud R. Why do psychiatrists neglect religion? British Journal of Medical Psychology 68(2):169-178; 1995.

24. Kroll J. Religion and Psychiatry. Current Opinion in Psychiatry 8:335-339; 1995.

Christina L. Glenn is currently in her final year at Broadview Heights High School (Johnson City, Tennessee, USA) and the analysis reported in this issue of the $M J M$ was completed during the summer semester of 1997 under the supervision of researchers affiliated with the Kellogg Community Partnerships Program at East Tennessee State University (Johnson City, Tennessee, USA). Ms. Glenn is planning to pursue an undergraduate degree with a major in Statistics at the University of Tennessee, Knoxville. Beyond her undergraduate degree, Ms. Glenn is considering medical school or a theological seminary, but is as-of-yet undecided. 